\title{
MOAR theory: a new system energy-saving method for Industrial Circulating Cooling Water System
}

\author{
ZHANG Hehui ${ }^{1,}$,, QU Yingjie ${ }^{2, b}$ \\ ${ }^{1}$ College of Energy Science and Engineering, Central South University, Changsha 410083, Hunan, China \\ ${ }^{2}$ Hunan M\&W Energy Saving Tech.Co.Ltd. , Changsha 410208, Hunan, China \\ ahehuizhang@csu.edu.cn, bpump118@163.com
}

\begin{abstract}
Keywords: Energy saving; Circulating water system; System engineering; Pump
Abstract. Due to the high complexity and strong coupling of industrial circulating cooling water system, single and isolated technology can never fulfill the energy-saving need. Thus a system energy-saving theory named MOAR was proposed and explained with practice, including four principles: management of system working, optimization of process demand, adjustment of energy feed and rise of component efficiency. An actual energy conservation project case of an organic chemical plant guided by the MOAR theory was presented. With the measures of flow rate reduce, pump replace, component work efficiency enhancement, and continuous production management means, a system power saving rate of $32.9 \%$ has been made in that project. The success of energy-saving practice illustrated the guidance significance of the MOAR theory.
\end{abstract}

\section{Introduction}

Industrial circulating water system, consisting of water pump, heat exchanger, cooling tower and pipe network, is widely used in various industries for the cooling of production equipment and material. As the operation base of fluid process industries, industrial circulating cooling water system consumes huge amounts of energy. Take the petrochemical industry as an example, just the electrical energy consumption of circulating pumping takes up $8 \% \sim 10 \%$ of the total energy required for production[1]. Thus the energy saving of industrial circulating cooling water system becomes the focus of research and attention. ZHANG et al. [2] designed a kind of energy-saving temperature control method for cooling water on the basis of process demand, and it can ensure better energy-saving effect. QIN et al. [3] proposed to use heat pump to replace cooling tower for water cooling and recovering waste heat in hot-stamping power system, and the recovered heat can be utilized for production and workers bathing. LIU et al. [4] invented a novel phosphorus reaction tower with aiti-corrosion circulating water wall, which improves the security and economy of the whole production line. Field and Ellert[5] emphasized the importance of operator training for energy-saving in a plant producing chilled water, and they pointed out that correct and skillful manipulation helps to increase energy efficiency. Although a lot of ways have been proved to be useful for energy-saving in industrial circulating water system, including the improvement of equipment, process routing and production management, there are few reports concerning comprehensive and systematic energy-saving method, which takes all factors into considering and integrates varied technology from different sources and providers for optimal system energy efficiency.

Under this circumstance, QU Yinjie, CEO of Hunan M\&W Energy Saving Tech.Co.Ltd. , has developed a system energy-saving theory named MOAR for fluid process industries [6]. In this paper, we firstly introduced the idea of MOAR theory, and then explained the four main principles of energy-saving. Finally, we discussed the application of MOAR theory associated with one construction project case occurring at the circulating water system of an organic chemical plant. 


\section{MOAR system energy-saving theory}

Although served in different fluid process industries, all industrial circulating water systems can be divided into four subsystems: cooling subsystem, pumping subsystem, distribution subsystem and service subsystem, and typical equipments of each of them are cooling tower, water pump, control valve and heat exchanger respectively. Due to the nonlinear, complexity and strong coupling between each subsystem and production unit, it is not easy to achieve satisfactory energy efficiency by just single or isolate way without disturbing the normal material and thermal balance. Instead, we propose a system energy-saving theory based on the practice of hundreds of energy-saving reconstruction projects. And the main opinion of MOAR theory is that the energy efficiency of industrial circulating water system can be raised as follows:

(a) Management of system working: aiming at enhancing production schedule quality, the expert system can obtain most optimal decision of production dispatch by analyzing historical and on-site monitoring data, which helps to keep the balance between energy consumption and production quality. Besides, this principle also requires adequate operator training and appropriate organization motivation on energy conservation.

(b) Optimization of process demand: with the premise of deep understanding of process design and running characteristics, the energy demand of terminal equipment should be optimized precisely according to dynamic production load. For circulation water system, most energy is used by heat exchangers for the cooling of process fluid, so cost-optimal flow rate and pressure value of circulating water should be set exactly.

(c) Adjustment of energy feed: it is the momentum transport, energy transport, quality transport and reaction engineering that control over the whole fluid process system, and all of them can be controlled by energy feed from outside. After understanding the optimum process demand, the energy feed should certainly be adjusted in proportion to minimize the excess of energy supply. For example, when the hourly water-demand decreases, the opening of valve controlling that branch should also be reduced timely.

(d) Rise of component efficiency: increase the efficiency as high as possible by the improvement of structure, material and matching degree of original production component, or just replace it into new generation component with higher efficiency. Needless to say, this principle is the most direct way and often plays an effective role.

Each of the above four principles begins with the letter $\mathrm{M}, \mathrm{O}$, A and $\mathrm{R}$ respectively, which form the MOAR theory. Although every principle can guide the energy-saving reconstruction more or less, the combine of them can achieve most satisfactory energy efficiency. By the statistics of more than 127 projects carried out by Hunan M\&W Energy Saving Tech.Co.Ltd., involving iron\& steel industry, power industry, petroleum and chemistry industry, the average system energy efficiency could be enhanced by $27.5 \%$.

\section{Case analysis and discussion}

In this part, we illustrate the application of MOAR theory by analyzing a project case. The case is about the energy-saving reconstruction project of the circulating water system of Sinpo Chemistry (Taixing) Co.Ltd., which serves the 3 million ton per year polyethylene production line. The general layout scheme of the circulating cooling water system is shown in Figure. 1. In Fig.1, there are three cooling towers marked with $\mathrm{C}_{1}, \mathrm{C}_{2}$ and $\mathrm{C}_{3}$, four water pumps marked with $\mathrm{P}_{1}, \mathrm{P}_{2}, \mathrm{P}_{3}$ and $\mathrm{P}_{4}$, and three heat exchanger unit marked with $\mathrm{H}_{1}, \mathrm{H}_{2}$ and $\mathrm{H}_{3}$. Each heat exchanger unit consists of several heat exchanger equipments. There is a water storage basin lies between cooling towers and pumps, which receives cooled water form cooling towers and supply it to pumps. In this system, pumps with frequency operation are the main energy consumption components, and pump $\mathrm{P}_{4}$ is used as backup. The original four pumps are not in the same type and the specifications are illustrated in Table 1. 


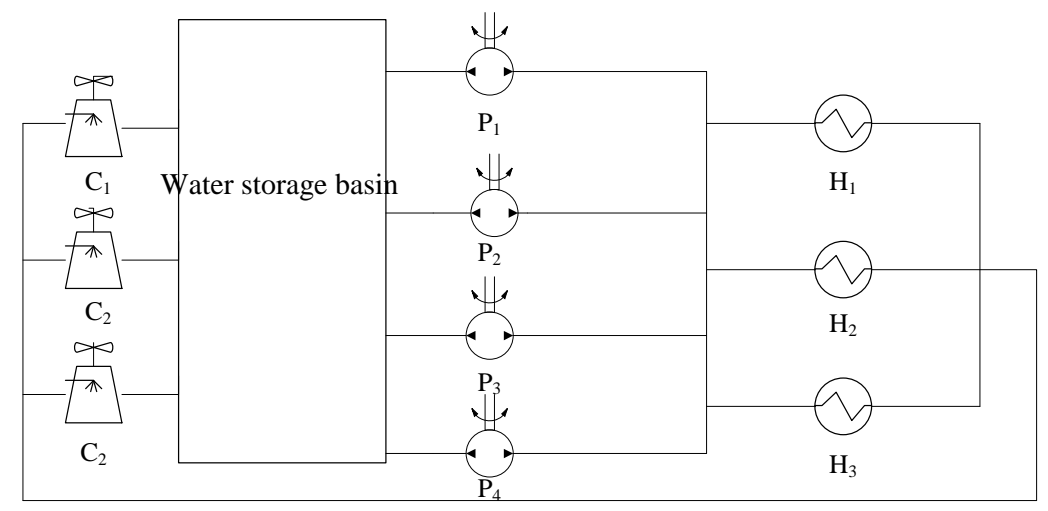

Fig. 1. General layout scheme of the circulating cooling water system

Table 1. Specification parameters of original pumps

\begin{tabular}{ccccccc}
\hline \multirow{2}{*}{ Pump mark } & $\begin{array}{c}\text { Flow rate } \\
\mathrm{m}^{3} / \mathrm{h}\end{array}$ & $\begin{array}{c}\text { Head } \\
\mathrm{m}\end{array}$ & $\begin{array}{c}\text { NPSHr } \\
\mathrm{m}\end{array}$ & $\begin{array}{c}\text { Rotate speed } \\
\text { r/min }\end{array}$ & $\begin{array}{c}\text { Efficiency } \\
\%\end{array}$ & $\begin{array}{c}\text { Motor power } \\
\mathrm{kw}\end{array}$ \\
\hline $\mathrm{P}_{1} \sim \mathrm{P}_{3}$ & 4800 & 56 & 6.5 & 980 & 82.5 & 1000 \\
$\mathrm{P}_{4}$ & 2100 & 56 & 6.7 & 1480 & 85.7 & 500 \\
\hline
\end{tabular}

With the guidelines of MOAR theory, the technical reform has been made into the following five steps:

Step I: Reduce the flow rate of circulating water passing some heat exchangers. After long-time temperature test of heat exchangers, we found out that for about one third of heat exchangers, the outlet temperature of process fluid was significantly lower than design value. So we recalculated cooling water flow rate with thermal balance equations and decided to reduce it by about $8 \% \sim 13 \%$.

Step II: With reduced flow rate demand, the pumping supply should also be adjusted. Unlike the frequency conversion method, we replaced the pumps directly with lower flow rate parameters. The specifications of replaced four pumps are illustrated in Table 2.

Table 2. Specification parameters of repalced pumps

\begin{tabular}{ccccccc}
\hline \multirow{2}{*}{ Pump mark } & $\begin{array}{c}\text { Flow rate } \\
\mathrm{m}^{3} / \mathrm{h}\end{array}$ & $\begin{array}{c}\text { Head } \\
\mathrm{m}\end{array}$ & $\begin{array}{c}\text { NPSHr } \\
\mathrm{m}\end{array}$ & $\begin{array}{c}\text { Rotate speed } \\
\text { r/min }\end{array}$ & $\begin{array}{c}\text { Efficiency } \\
\%\end{array}$ & $\begin{array}{c}\text { Motor power } \\
\mathrm{kw}\end{array}$ \\
\hline $\mathrm{P}_{1} \sim \mathrm{P}_{3}$ & 4320 & 51 & 7.2 & 980 & 90.3 & 800 \\
$\mathrm{P}_{4}$ & 1750 & 51 & 7.1 & 1480 & 89.8 & 350 \\
\hline
\end{tabular}

Compared with Table 1, it is easy to find out in Table 2 that both flow rate and head of the pumps becomes lower, and the efficiency increases remarktablely, which brings lower motor power. The NPSHr (required net positive suction head) of replaced pumps increases by $0.7 \mathrm{~m}$ (for pump $\mathrm{P}_{1} \sim \mathrm{P}_{3}$ ) and $0.3 \mathrm{~m}$ (for pump $\mathrm{P}_{4}$ ) respectively. However, considering the position of pump inlet is usually under the water lever of water storage basin, so the infulence of the rise of NPSHr can be ignored.

Step III: Raise the work efficiency of pumps and cooling towers. For pumps, the hydraulic model was redesigned referring to actual operating condition through CFD study, with a 4.1\% 7.8\% efficiency enhancement. For the pump $\mathrm{P}_{1} \sim \mathrm{P}_{3}$, the $3 \mathrm{D}$ graphic model of optimized fluid domain including sunction water chamber, impeller region and pressurized water chanmber is shown in Fig.2, and high quality structure mesh of the rotating impeller subdomain is shown in Fig.3. While for cooling towers, the packing had been changed to realize better cooling effect. With other conditions unchanged, the outlet water temperature of the improved cooling tower with replaced high performance packing becomes $1.5^{\circ} \mathrm{C}$ to $3.0^{\circ} \mathrm{C}$ lower.

Step IV: Tighten production management and continuously improve process operation condition. Undesirable valve resistance loss had decreased to minimum and obvious water leakage had been avoided. The performance of energy reduce inspired the worker's work enthusiasm and encouraged them to concern the energy-saving job more than before. 
According to the one-year statistics made by plant proprietor, compared with before, total pump power decreases from $3527 \mathrm{~kW}$ to $2365 \mathrm{~kW}$, which means a 32.9\% power saving rate. The cost saving per year sums up to more than 6 million in RMB ( $¥ 0.60 / \mathrm{kWh}$ for electricity cost), with reduce of $\mathrm{CO}_{2}$ discharge about 18 million ton each year.
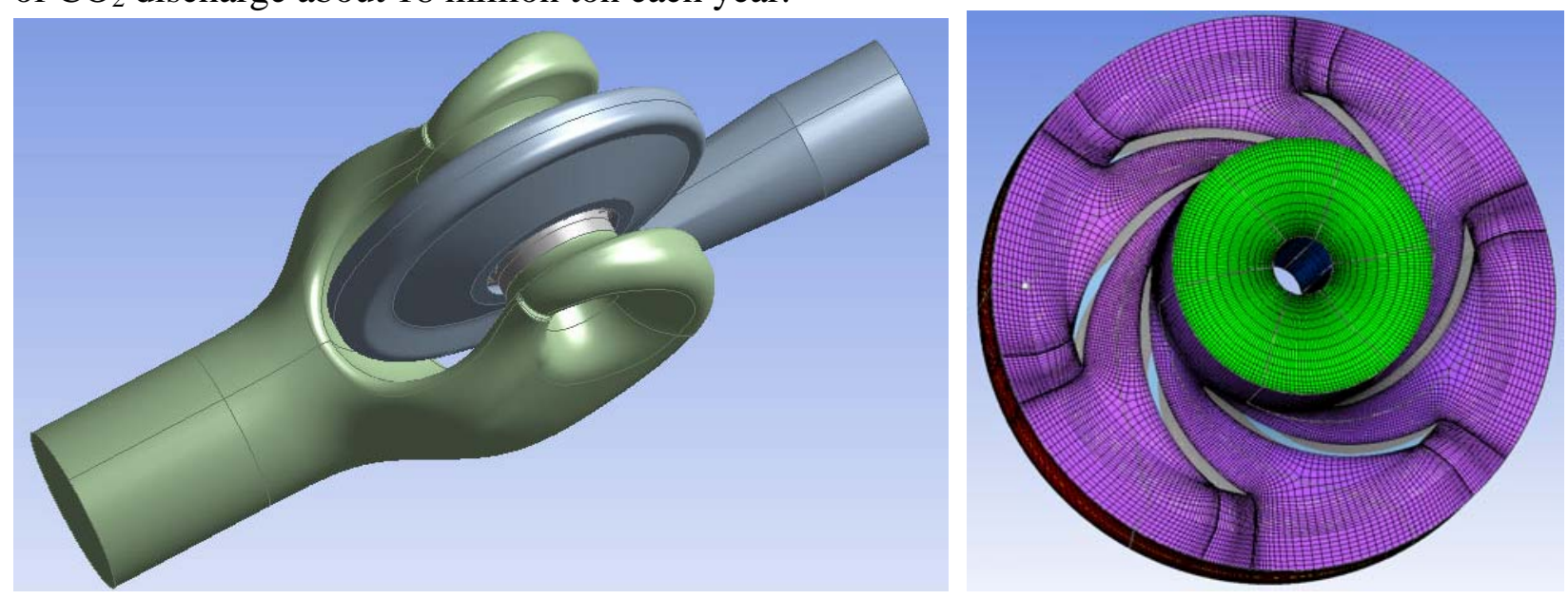

Fig. 2. 3D modeling of fluid domain

Fig.3. High quality structure mesh of roating subdomain

\section{Conclusion}

A new kind of system energy-saving method for industrial circulating cooling water system named MOAR is proposed, which has been proved to be valid by project practice. The MOAR theory is made of four different principles with wide range of application. The using value of the MOAR theory relies on the integrating and coordination of varies kinds of energy-saving technology including equipment, craft, process control and management, which may come from different service providers. Therefore, the MOAR theory should never stop absorbing new energy-saving ideas and elements.

\section{Acknowledgements}

This work was financially supported by the School Enterprise Cooperation Project "MOAR System Energy-saving Theory and Application" made by Central South University and Hunan M\&W Energy Saving Tech.Co.Ltd..

\section{References}

[1] Information on http://www.ccin.com.cn(In Chinese)

[2] L.Z.Zhang, S.H.Jia, X.J. Zhao, Y.Sun and G.D.Shi: Advanced Materials Research, Vol. 512-515(2012), p. 1163-1166

[3] P.P.Qin, H.Chen, L.L.Chen, C.Wang, X.X.Liu, X.J.Hu, L.N.Yu and S.K.Liu: Clean Technologies and Environmental Policy, Vol.15(2013), P. 741-746

[4] B.Q.Liu, F.L.Qin, J.Z.Jiang and Z.J.Jin: Journal of Materials Engineering and Performance, Vol.21(2012), P. 308-312

[5] B.S.Field and D.Ellert: ASHRAE Transactions, Vol.118(2012), P. 309-316

[6] H.H.Zhang, S.X.Deng and Y.J.Qu: Energy and energy conservation, Vol.119(2015), P. 85-86(In Chinese) 